\title{
INTELECTUALES PÚBLICOS, INTELECTUALES CRÍTICOS: LA INTELECTUALIDAD INDÍGENA EN AMÉRICA LATINA
}

Claudia Zapata Silva 


\section{CLAUDIA ZAPATA SILVA}

Es Licenciada en Historia, Profesora de Educación Media con mención en Historia y Geografía, Magíster en Estudios Latinoamericanos y Doctora en Historia con mención en Etnohistoria, títulos y grados otorgados por la Universidad de Chile. Profesora asociada de la Facultad de Filosofía y Humanidades de la Universidad de Chile. En 2015 recibe el Premio de Ensayo Ezequiel Martínez Estrada de Casa de las Américas (Cuba) por el volumen Intelectuales indígenas en Ecuador, Bolivia y Chile. Diferencia, colonialismo y anticolonialismo. 


\section{INTELECTUALES PÚBLICOS, INTELECTUALES CRÍTICOS: LA INTELECTUALIDAD INDÍGENA EN AMÉRICA LATINA}

No puede haber paz, sin igualdad; este es un valor intelectual que es necesario reiterar, demostrar $y$ fortalecer desesperadamente.

E. Said (2006:169).

En 1911, Anales de la Universidad de Chile publicó la primera entrega de "Comentarios del pueblo araucano", del profesor normalista Manuel Manquilef ${ }^{16}$. Un año después, la misma revista publicaba "Las últimas familias y costumbres araucanas", de Tomás Guevara $^{17}$, donde la figura de Manquilef aparece confinada al lugar de informante de la que se transformaría en una importante obra etnográfica. El tiempo se encargaría de fijar esas imágenes: Guevara etnógrafo y Manquilef informante. Noventa años más tarde, el Centro de Estudios y Documentación Mapuche Liwen (CEDMLiwen), creado por intelectuales y activistas de este pueblo, recuerda la figura de Manquilef, enfatizando su condición de intelectual mapuche. En este contexto, es considerado como el primero en practicar la escritura bilingüe y en desenvolverse en el género del ensayo etnográfico, desde el cual analizó las características y los códigos de funcionamiento de una sociedad mapuche recientemente invadida e incorporada al Estado nación chileno.

Reconociendo la fructífera pero a la vez conflictiva relación entre Manquilef y Guevara, en que la publicación del primero en los Anales de la Universidad de Chile pareció constituir el punto de inflexión que marcaría el distanciamiento definitivo entre ambos (Ancán), CEDM-Liwen repara en el olvido de la obra independiente del intelectual mapuche, pese al logro que significó su reconocimiento como autor por parte de la principal institución cultural del país: la Universidad de Chile. El trabajo del CEDM-Liwen, en especial de José Ancán, no se limita al rescate de la figura, sino que avanza hacia la reivindicación de Manquilef como intelectual, sometiendo su obra a nuevos análisis y restituyendo -la palabra es de Ancán- la autoría que cabría consignarle en la obra de Guevara, esto último por medio de un

16. Otras dos partes de ese escrito fueron publicados por la misma revista en 1914. El texto completo fue publicado como libro por Imprenta Cervantes en 1911.

17. También publicado como libro al año siguiente de su aparición en los Anales de la Universidad de Chile. 
hecho concreto: la reedición de la primera parte y medular de "Las últimas familias y costumbres araucanas", titulada "Historias de familias", y señalando como autores a la dupla Guevara-Manquilef ${ }^{18}$.

El trabajo de Liwen en torno a la figura señera de Manuel Manquilef nos refresca la memoria sobre un hecho relevante pero a la vez excepcional: el reconocimiento y la legitimación que la institucionalidad académica hizo de un autor mapuche a comienzos del siglo XX. Por casi un siglo no se registra otro reconocimiento de similar envergadura por parte del campo cultural chileno, pese al incremento de los letrados indígenas, que se fueron instalando en la periferia de dicho campo. Es más, se podría afirmar que el interés por las escrituras indígenas se reactivaría recién en los años 90, con el movimiento poético donde destacan las figuras centrales de Jaime Huenún, Elicura Chihuailaf, Graciela Huinao y Lorenzo Aillapán, entre muchos otros. Paralelamente, aquellos autores que producen ensayos interpretativos y escrituras que muestran resultados de investigaciones desarrolladas en el ámbito de las humanidades y las ciencias sociales (género que entre los autores mapuches encuentra su primer antecedente en Manquilef) no gozan de la misma visibilidad, por lo tanto es posible afirmar que una parte importante de la producción intelectual mapuche continúa sin ser suficientemente considerada, y ello pese a algunos hechos editoriales importantes que se han producido durante los últimos quince años ${ }^{19}$.

El hecho de que la aparición de Manquilef en los Anales de la Universidad de Chile no fuera suficiente para que trascendiera en el tiempo como autor, sino como el informante (nativo) y colaborador privilegiado del etnógrafo Tomás Guevara, nos plantea el siempre espinudo tema de la legitimación, el reconocimiento y el lugar que estos autores ocupan en el campo intelectual, tanto en Chile como en los demás países latinoamericanos, donde se advierten dificultades y conflictos parecidos. Esta similitud tiene su raíz en sociedades todavía racializadas (Wade, Briones), con huellas coloniales (Rivera), que determinan la posibilidad de acceso a los sistemas

18. Tras esta intervención, que puede catalogarse con toda propiedad como una intervención política, que alcanzará también la revisión de la parte en mapudungun y la refonemización de acuerdo a los usos consensuados de la lengua en el seno del movimiento mapuche (modificando incluso el apellido del profesor normalista), el volumen que ve la luz el año 2002 se titula Kiñe mufü trokiñche ñi piel. Historias de familias. Siglo XIX, de los autores Tomás Guevara y Manuel Mañkelef.

19. Me refiero a la publicación de i...Escucha, winka...! Cuatro ensayos de Historia Nacional Mapuche y un epílogo sobre el futuro, de Pablo Marimán, Sergio Caniuqueo, José Millalén y Rodrigo Levil (Lom, 2006); Autodeterminación. Ideas políticas mapuche en el albor del siglo XXI, de José Marimán (Lom, 2012); y Malon. La rebelión del movimiento mapuche 1990-2013, de Fernando Pairicán (Pehuén, 2014). 
educativos (y la calidad de ese acceso una vez que se produce), condición necesaria para la conformación de intelectualidades indígenas. Es entonces la racialización, ese modo particular de subalternización de los pueblos indígenas y afrodescendientes (desde la conquista europea en que fueron homogeneizados bajos las categorías de indios y negros), concretada en distintas formas de exclusión social, un factor que no puede ser obviado a la hora de analizar la difícil conformación de intelectuales entre estos sectores de la sociedad latinoamericana, pues ella explica en gran medida lo tardío y a la vez conflictivo de este proceso, que recién podemos identificar en el siglo XX con pioneros como Manquilef y otros ejemplos que se replican en distintos lugares del continente, pero que se amplía recién en la segunda mitad de esa centuria, a la par de la masificación de los sistemas educativos (Zapata).

Esta perspectiva implica una mirada histórica y en estrecho vínculo con la sociedad de las figuras intelectuales, de ahí la pertinencia del concepto de campo intelectual que propone Pierre Bourdieu, porque sitúa en un primer plano las relaciones de poder y las jerarquías que allí operan. En el caso de América Latina, estamos hablando de un campo intelectual donde las jerarquías entre las clases sociales tienen un peso fundamental, pero que, insisto, también es un campo racializado, atravesado por los estereotipos y jerarquías particulares que ello implica y que coloca a indígenas y afrodescendientes en una doble posición de subalternidad (triple si consideramos la variable de género cuando se trata de autoras). A su vez, esto significa reconocer un hecho no menor: que la posición en el campo y la valoración de la obra no tiene que ver exclusivamente con la calidad de esta última, sino preferentemente con la posición del autor en la sociedad y con las jerarquías culturales que en ella predominan. Por este motivo es que tanto el acceso como los posicionamientos y las trayectorias de los autores que provienen de sectores racializados constituyen temas de fundamental importancia (Zapata y Stecher).

En el caso específico de los indígenas, existe un sector creciente y a la vez heterogéneo de intelectuales que realiza un trabajo de producción autorial en condiciones por lo general precarias, instalados en la periferia de la institucionalidad académica, ejerciendo la docencia externalizada, sin vínculo estable con la universidad o institución respectiva, aunque con notables avances en algunos países, destacándose el caso de Bolivia, donde crece el número de académicos y académicas que acceden a plazas en las universidades (esto en comparación con períodos anteriores). Otros académicos, o incluso los mismos que imparten este tipo de docencia universitaria, combinan su trabajo de autores con trabajos profesionales en organismos privados y públicos que demandan su experticia profesional, en especial los segundos, que de acuerdo a las estadísticas aparecen como los principales empleadores de los profesionales indígenas, ese segmento mayor del cual proceden los intelectuales (Hall y Patrinos). 
Se trata, entonces, de un acceso real al campo intelectual pero en posiciones todavía periféricas, donde son otros los sectores que detentan hegemonía, los que o bien reconocen y alientan esta presencia (sobre todo en el caso de la literatura), o bien la descalifican. Otros simplemente la omiten o no se han dado cuenta de ella debido a factores de orden político que derivan en la invisibilización de los indígenas letrados, como se analizará más adelante. Pese a ello es posible encontrar un sector de intelectuales con una vasta producción escrita y especializada en distintos ámbitos del conocimiento desde hace ya varias décadas: en Bolivia desde los años 60, en Ecuador desde los 70 y en Chile también durante esa década, y ello solo por mencionar el proceso que permite identificar un movimiento en cada caso, con una creciente presencia en los respectivos campos intelectuales, pues lo cierto es que la tradición de escrituras indígenas posee una larga data en el continente, también las controversias en torno a ellas, desde la figura de Guamán Poma hasta nuestros días.

Esta nutrida producción escrita, a la que desde hace dos décadas se suma aquella que es publicada exclusivamente por medios electrónicos, los mismos que a su vez replican textos que tienen una primera versión impresa, tiene una importante presencia en los espacios públicos de los distintos países. Por lo tanto, si bien no acceden de manera significativa a las grandes editoriales, a las revistas más prestigiosas o a los suplementos culturales de la prensa escrita, sí han constituido circuitos con sus respectivos públicos (Fraser habla de "contrapúblicos" para referirse a este proceso de desigualdad en el acceso al espacio público). Ese circuito constituye un entramado social donde tienen enorme relevancia los movimientos indígenas, conformados por distintas organizaciones e individuos, los intelectuales entre ellos.

En lo que respecta al espacio público "nacional", la presencia allí es menos continua y por lo mismo los episodios que marcan una irrupción en él son importantes, por las vallas que se han tenido que sortear y porque, casi siempre, constituye un gesto crítico por parte del intelectual indígena, fuertemente asociado a las luchas indígenas que asomaron en el continente hace ya más de tres décadas. Estos intelectuales a veces participan como militantes de alguna organización o movimiento y en la mayoría de los casos son activistas de causas que reivindican una particularidad cultural y las exclusiones que históricamente los han afectado (los intelectuales son, de hecho, quienes articulan esa lectura con profundidad histórica y densidad tanto teórica como política). Las intervenciones públicas de los intelectuales indígenas, me refiero con ello a sus publicaciones, charlas, entrevistas, contienen esta densidad y articulación que los distingue. A través de ellas transmiten su lectura crítica de las respectivas historias nacionales, de la cultura "legítima", de la centralización "metropolitana" (el término no es menor si atendemos al diagnóstico de continuidad colonial que elabora y suscribe el grueso de la intelectualidad indígena 
del continente), de la compulsión civilizadora, de los nacionalismos conservadores que continúan vigentes sobre todo en la relación de los estados con los pueblos indígenas (y ello pese al aggiornamento multicultural de la mayoría de ellos), y de sociedades donde perviven las jerarquías raciales.

La contundencia de estas perspectivas está adquiriendo, pese a todo, mayores espacios para su despliegue, lo que se explica por las transformaciones políticas que han sido provocadas en gran medida por los propios movimientos indígenas (leyes y reformas constitucionales en algunos casos; refundaciones nacionales en otros, como está ocurriendo en Bolivia, donde las dirigencias indígenas han alcanzado posiciones de hegemonía). En países como Chile, donde todavía existe enorme ceguera con respecto a la diversidad cultural de su sociedad y de las tensiones políticas que existen en torno a ella (el apelativo de "conflicto indígena" condensa esta ignorancia), este tipo de intervenciones públicas constituyen disrupciones necesarias, que contribuyen al debate o al menos a la posibilidad de este por cuanto instalan voces que cada vez se va haciendo más difícil no considerar (me refiero, en concreto, a que cada vez se vuelve más incómodo pasar por alto al historiador indígena, al periodista indígena, al poeta indígena, etc., cuando se habla de sus pueblos).

Un asunto paradójico es que esta visibilización significa que se hable de ellos como autores y como intelectuales justo cuando el escepticismo frente a los intelectuales crece a límites insospechados en todo el espectro social y político ${ }^{20}$. En otros trabajos he analizado largamente esta situación confusa (Zapata) y me conformo con señalar aquí que toda la connotación negativa que rodea en la actualidad al concepto de intelectual conspira contra la visibilización del proceso histórico de configuración de los intelectuales indígenas, contra la evaluación de esta labor y contra su eventual reconocimiento, tanto en el ámbito político como en los campos intelectuales e incluso al interior de los propios movimientos indígenas, donde también se encuentra instalada la controversia.

A este descrédito de los intelectuales se agregan otros factores en el caso específico de los pueblos indígenas que interfieren de manera igualmente negativa en la valoración de la función intelectual. Me refiero a una concepción de lo indígena que pone énfasis en la externalidad respecto de Occidente y de la modernidad.

20. Vivimos una época en la que se condenan las ideologías, las grandes narrativas y todo tipo de representación, frente a lo cual se oponen las prácticas concretas y la acción directa, sensibilidad que podríamos llamar posmoderna si atendemos a algunos de sus exponentes (Hardt y Negri, Virno). Una dicotomía en la que pervive el antiintelectualismo de otras épocas, como el de los años 60 en América Latina, que sin negar a los intelectuales les imponía la ética de la revolución, que pasaba por el compromiso militante y las prácticas “concretas” (Gilman). 
Con variaciones en el tiempo, esta es la arena que han pisado y compartido tanto los sectores que han dominado a los indígenas (imponiendo jerarquías culturales, usurpando sus recursos y explotando su mano de obra), como los que han visto con buenos ojos su diferencia e incluso han invertido energías en su preservación (que a su vez constituyen un amplio abanico, desde los que aíslan esa diferencia de la explotación y la pobreza, hasta los que solidarizan con sus luchas). Como sea, en estas representaciones encuentran poca cabida los procesos históricos de imbricación entre indígenas y no indígenas, y las transformaciones socioculturales que se han producido en unos y otros como parte de esta historia.

El punto que acabo de referir remite a una constelación ideológica que hunde sus raíces en el tiempo, para transportarnos a esa construcción primigenia de una alteridad inferior cuyo origen se ubica en la conquista de América por parte de las potencias europeas. Desde entonces, el dominio impuesto establece una dialéctica entre la dimensión material y la ideológica, a tal punto que resulta imposible separarlas. La colonización de los pueblos indígenas -un proceso de largo aliento que se extiende hasta nuestros días- requirió de construir una frontera, de remarcarla y reproducirla. La confinación de los indígenas al espacio de la cultura, comprendida como permanencia (costumbres, vestimentas, ritos, paisajes) y revestida de racismo al vincular a esa cultura con un fenotipo y una psicología colectiva, forma parte central de esta construcción de frontera. Su peso y poder se manifiesta en la vigencia del vínculo colonial que se puede constatar entre pueblos indígenas y las ahora sociedades nacionales, lo que Pablo González Casanova denominó "colonialismo interno", en diálogo productivo con los movimientos de liberación nacional, especialmente los que tenían lugar en África durante los años 60. Una tesis recogida, recreada y extendida por los movimientos y la intelectualidad indígena a fines de esa década, conformando la piedra angular de la interpretación y de la crítica indígena en la actualidad ${ }^{21}$, donde radica toda su carga política, difícil de digerir por los ámbitos disciplinarios y los círculos académicos más profesionalizados (el concepto de profesional lo tomo de Said, 1996).

El peso gravitante que tiene todavía esta construcción ideológica se observa en la vigencia de perspectivas esencialistas que subyacen a los discursos sociales (incluidos los de la intelectualidad, ubicada tanto dentro como fuera de los espacios académicos), que se refleja en el gesto de eludir las configuraciones culturales

21. Precursor y emblemático será el libro del intelectual aymara Fausto Reinaga (Bolivia), titulado La revolución india, donde propone la lectura de la problemática indígena en clave anticolonial, en sintonía con los movimientos de liberación nacional y tomando como referentes teóricos a sus principales figuras, en especial a Frantz Fanon, autor afrodescendiente de Martinica, teórico anticolonial y alto dirigente del Frente de Liberación de Argelia (FLN). 
complejas que surgen de la relación entre sociedades y culturas, más aún cuando ese vínculo es tan desigual como el que existe entre sujeto indígena y sociedad nacional. En este caso, la pureza y la autenticidad parecen imponerse como condiciones para identificar "lo indígena" (Briones). Por el contrario, cuando el indígena circula por espacios no tradicionales y adquiere competencias identificadas como metropolitanas y modernas, se erige como un ser sospechoso, en especial cuando transita por la ciudad y recurre a la escritura como medio de expresión. En primer lugar, sospechoso de no ser indígena, pero también sospechoso a nivel social y político. Un ejemplo claro han sido las categorías para nombrar estos desplazamientos de la idea esencial de indio como sujeto "otro": en Ecuador se habló de "indios evolucionados" y en Bolivia de "cholos", ese mestizo indianizado poco confiable, un potencial traidor del que todos parecen tomar distancia. Salvador Romero, en su estudio sobre la intelectualidad boliviana de las primeras décadas del siglo XX (incluidos los canonizados Alcides Arguedas y Franz Tamayo), pone de manifiesto con enorme lucidez esta tensión al interior de un naciente campo intelectual cuando señala como principal causa de esta denostación “...la habilidad del cholo para adoptar las modalidades de pensamiento y comportamiento occidentales, borrando las diferencias con los sectores tradicionales de privilegio, cuyo dominio provenía del monopolio que tuvieron de esos comportamientos. Por eso cuanto más asimilados

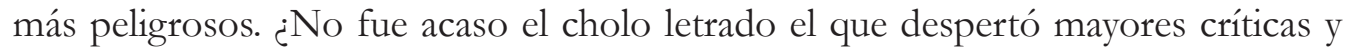
rechazos?” (37). Mirar el asunto desde este ángulo pone de manifiesto lo artificioso que resulta aislar la diferencia cultural del contexto en que esta se reproduce y de las luchas por el poder que experimenta una sociedad, así como la necesidad de comprenderla como una diferencia históricamente constituida.

En el caso de los intelectuales indígenas esa sospecha aparece con excesiva frecuencia, a tal punto que para muchas personas resulta un desajuste mayúsculo vincular la categoría de indígena con la de intelectual, escritor, historiador, antropólogo, sociólogo, entre muchas otras (la anécdota que comenta Pedro Cayuqueo de la señora que no puede entender que él sea mapuche y al mismo tiempo periodista es particularmente decidora). Pero cuando la evidencia hace imposible obviar su condición de autor (cuando nos encontramos con un libro, artículo o columna de opinión), se los llega a reconocer como tales, pero suponiendo que esa autoría expresa una voz colectiva y una cultura ancestral. Su especificidad como intelectual, la función crítica que cumplen en el espacio público y su individualidad son recurrentemente subsumidas por ese imperativo de representación colectiva.

La persistencia de estas concepciones y su enraizamiento en prácticamente todos los sectores de la sociedad es un hecho que llama la atención si se considera que existe una trayectoria de intelectualidad crítica que en América Latina ha pensado los cruces, las intersecciones y los nuevos procesos surgidos del encuentro/choque 
entre distintos pueblos, una colisión dramática que se encuentra en el origen mismo de la historia continental y que se reformula en distintos momentos históricos, hasta hoy. Una relación conflictiva y desigual que no ha concluido con la diferencia de los distintos pueblos indígenas y afrodescendientes, pero que sin embargo la transforma y sitúa en el centro de procesos de construcción de subalternidad (se pueden mencionar referentes ineludibles de esta posición argumentativa: los cubanos José Martí y Fernando Ortiz, los peruanos José Carlos Mariátegui y Antonio Cornejo Polar, el uruguayo Ángel Rama, la boliviana Silvia Rivera Cusicanqui y autores afrodescendientes del Caribe, entre los que destaca el martiniqués Frantz Fanon).

La conflictividad que rodea a los intelectuales indígenas y que he tratado de mostrar aquí pone en evidencia la trayectoria elitista, racista y clasista del campo intelectual. Pero de esto no tiene por qué desprenderse, desde mi perspectiva, una condena hacia los intelectuales. Hacerlo sería irresponsable. Muy por el contrario, la difícil situación de la intelectualidad indígena es un argumento a favor de la historicidad del campo y del aporte que puede y debe hacer a la democratización de nuestras sociedades.

Desde la perspectiva que he venido desarrollando aquí, el concepto de intelectuales deriva inevitablemente en la idea de esfera pública. Me doy cuenta ahora de que el estudio de los intelectuales indígenas (y más recientemente la comparación entre estos y los autores afrodescendientes del Caribe) me ha cautivado por esta dimensión del quehacer escritural y de su activismo. El concepto de intelectual continúa teniendo para mí una ineludible connotación política a la vez que constituye un concepto con la suficiente versatilidad como para identificar una intelectualidad con escasa presencia en la academia, y a la vez dar cuenta de los conflictos implicados en esta instalación periférica. Es probable que más que una reminiscencia sesentera, mi interés por los intelectuales que provienen de sectores racializados de la sociedad latinoamericana tenga que ver con una necesidad actual de revitalización del espacio público, de promover su complejidad, su heterogeneidad y la calidad de sus debates, con plena conciencia de los obstáculos que se presentan a la concreción de este propósito, principalmente los monopolios ideológicos en ámbitos como los medios de comunicación, la sociedad y la economía. Pese a todo aquello, es posible acceder y provocar cierto ruido, como he querido ejemplificar aquí con el caso de los intelectuales indígenas.

La coyuntura que actualmente experimenta la sociedad chilena, que parece sacudirse de la estabilidad soporífera que había imperado durante una transición democrática excesivamente larga, requiere de una esfera pública activa y de la 
participación de la mayor cantidad de actores en ella. Esto incluye, por cierto, a los intelectuales, cuya función en la sociedad ha dejado de ser analizada y pensada, o si se ha hecho, ha carecido de la intensidad y la pasión de otras épocas, imponiéndose más bien una percepción negativa que ha dado paso, de un lado, a superponer la acción de los movimientos sociales, y del otro, a disfrazar a los intelectuales (orgánicos del poder) de expertos, asesores, consultores e investigadores, una jerga que al menos para quien escribe resulta harto más rimbombante que hablar de intelectuales. Por otra parte, es fundamental tener presente que hay algo de tramposo en la pretendida objetividad y desideologización de los expertos, que suelen defender los intereses de ciertos grupos sociales para los que, además, muchas veces trabajan. Sigo con esto el alegato de Edward Said sobre el mapa de la intelectualidad contemporánea, donde distingue a trazo grueso entre profesionales (esos expertos que mencioné más arriba y que se pretenden apolíticos) y amateurs o francotiradores, esos que disparan al poder, que procuran su autonomía como condición necesaria para la crítica, que reconocen su condición de sujetos situados (su pertenencia a una clase social, un pueblo, una cultura) y que discuten desde ahí las jerarquías que se reproducen en una sociedad, así como las distintas formas de opresión. Se podría pensar, entonces, en la necesidad de reponer este debate sobre la función pública de los intelectuales y sus posibles aportes en los tiempos que corren, superando la ficción de la experticia objetiva que excluye a la ciudadanía y advirtiendo el potencial político de esta función, sobre la cual dice Said “....desde el momento mismo en que publicas ensayos en una sociedad has entrado a formar parte de la vida política; por eso, si no quieres ser político, no escribas ensayos o pronuncies conferencias" (1996:114-115).

Ángel Rama nos recuerda esta relación estrecha entre los intelectuales y la política en su estudio clásico La ciudad letrada, donde aporta abundantes evidencias de los vínculos que han existido entre campo intelectual y campo político en América Latina, a tal punto que una puede preguntarse cuándo es que los intelectuales no han estado en la arena pública, tanto aquellos orgánicos que defienden los intereses de quienes detentan la hegemonía, como los que la han cuestionado. Estos últimos tienen una larga trayectoria en esta función de francotiradores, ejercida desde distintas posiciones: la prensa, el magisterio, la universidad, la creación literaria y artística, las disciplinas. Esto me hace defender la figura de los intelectuales y reconocer esa genealogía de tradiciones críticas que no temieron confrontar los modelos de sociedad heredados, constituyendo vertientes emancipadoras que, situándose en la modernidad, al mismo tiempo la discuten y expanden, a contrapelo de los que se han sentido sus dueños.

Esta función crítica consiste, a grandes rasgos, en elaborar interpretaciones donde confluyen pasado y presente para develar las falacias de las exclusiones que 
han operado y que todavía operan en nuestras sociedades; promover el debate y la controversia en la esfera pública, confrontando a los círculos de poder, incluidos sus intelectuales; provocar también el debate e instalar disensos en el seno de los movimientos a los cuales adhiere; y por último, procurar su autonomía crítica hasta el límite que le sea posible, incluidas las orgánicas que representan las causas con las que se encuentra comprometido.

La heterogeneidad política de los intelectuales en la que he insistido, derivada de la diversidad social y cultural que representan, impide suscribir esa imagen de figuras excepcionales, privilegiadas y distanciadas del mundo con la que se los representa. El caso de los intelectuales indígenas permite discutir esas y otras asociaciones con bastante claridad por pertenecer a sectores dominados de la sociedad, que por un lado pone de manifiesto la historicidad del campo intelectual y sus jerarquías (la distinción entre dominantes y recién llegados que propone Bourdieu manifiesta aquí su pertinencia), y por el otro, el enorme aporte que implica esta presencia en la medida en que contribuye a su pluralidad y eventual democratización. Es la llegada de los que siempre habían sido representados para instalar en él una representación propia de la historia de sus pueblos, que colisiona con historias nacionales que los han negado: tanto cuando se los dejó fuera de sus fronteras geográficas y simbólicas, tratando muchas veces de exterminarlos, como cuando se les ofreció una integración condicionada a su asimilación cultural. Los intelectuales indígenas elaboran interpretaciones críticas de esa historia y debaten sobre la forma presente de las comunidades nacionales, del lugar que en ella tienen los pueblos con trayectorias y culturas distintas y de la necesidad de reformular sus vínculos. Su trabajo es, por lo tanto, también una contribución invaluable a la esfera pública, más aún en el contexto de efervescencia social que vivimos y que los pueblos indígenas adelantaron con la demanda por el reconocimiento político que han venido sosteniendo desde hace ya casi 30 años.

Pierre Bourdieu, en su difundida teoría sobre los campos, señala que la lógica del campo intelectual es la argumentación y la refutación, mientras que la del campo político sería la denuncia y la difamación. Existirían, agrega, traspasos y límites difusos entre uno y otro campo, pero cuando prevalece la lógica del campo intelectual entonces se fortalece la democracia (185). No debería evitarse entonces -mucho menos condenarse, como ha ocurrido más de una vez con la acusación de activistas que ha recaído sobre los intelectuales indígenas- esa relación imbricada entre intelectuales y política, pues se trata de una impureza que fortalece ese espacio público del cual todos y todas deberíamos sentirnos medianamente responsables. 


\section{REFERENCIAS}

Ancán, José. "Historias de familias. Restitución de autoría, voces e independencia, memorial de una derrota, antecedente para lo que vendrá”. Kiñe mufü trokiñche ñi piel. Historias de familias. Siglo XIX. Tomás Guevara y Manuel Mañkelef. Santiago: CEDM-Liwen / CoLibris, 2002a. 7-30.

Bourdieu, Pierre. Intelectuales, política y poder. Buenos Aires: Eudeba, 2000.

Briones, Claudia. La alteridad del cuarto mundo. Una deconstrucción antropológica de la diferencia. Buenos Aires: Ediciones del Sol, 1998.

Cayuqueo, Pedro. "Ser mapuche hoy". Azkintuwe, Temuco, 19 de abril, 2011.

Fraser, Nancy. Iustitiainterrupta. Reflexiones críticas desde la posición "postsocialista”. Bogotá: Siglo del Hombre Editores, 1997.

Gilman, Claudia. Entre la pluma y el fusil. Debates y dilemas del escritor revolucionario en América Latina. Buenos Aires: Siglo XXI Editores, 2012.

González Casanova, Pablo. Sociología de la explotación. México D. F.: Siglo XXI, 1978 (1969).

Guevara, Tomás y Manuel Mañkelef. Kiñemufütrokiñcheñi piel. Historias de familias. Siglo XIX. Santiago: CEDM-Liwen / CoLibris, 2002.

Manquilef, Manuel. "Comentarios del pueblo araucano (la faz social)". Anales de la Universidad de Chile. [En línea], 0 (1911): pp. 393-450.

. "Comentarios del pueblo araucano II. La jimnasia nacional (juegos, ejercicios i bailes)". Anales de la Universidad de Chile. [En línea], 0.72 (1914): pp. 239301.

. "Comentarios del pueblo araucano (Conclusión)". Anales de la Universidad de Chile. [En línea], 0.72 (1914): pp. 801-883.

Hall, Gillette y Patrinos, Harry A. (2005). Pueblos indígenas, pobreza y desarrollo humano en América Latina: 1994-2004. Resumen Ejecutivo. Washington: Banco Mundial.

Hardt, Michael y Negri, Antonio. Imperio. Buenos Aires: Paidós, 2002.

Reinaga, Fausto. La revolución india. La Paz: Ediciones PIB / Cooperativa de Artes Gráficas, 1969.

Rivera Cusicanqui, Silvia. "La raíz: colonizadores y colonizados". Violencias encubiertas en Bolivia, Vol. 1, "Cultura y Política”. Xavier Albó y Raúl Barrios (coord.). La Paz: Aruwiyiri / CIPCA, 1993. 25-139. 
Romero, Salvador. El nacimiento del intelectual en Bolivia. La Paz: Neftalí Lorenzo E., 2009.

Said, Edward. Representaciones del intelectual. Barcelona: Paidós, 1996. . Humanismo y crítica democrática. La responsabilidad pública de escritores e intelectuales. Barcelona: Random House Mondadori, 2006.

Virno, Paolo. Gramática de la multitud. Para un análisis de las formas de vida contemporáneas. Buenos Aires: Ediciones Colihue, 2003.

Wade, Peter. Raza y etnicidad en Latinoamérica. Quito: Editorial Abya Yala, 2000.

Zapata, Claudia y Stecher, Lucía. "Representación y memoria en escrituras indígenas y afrodescendientes contemporáneas". Revista Casa de las Américas, (280). En prensa.

Zapata, Claudia. Intelectuales indígenas en Ecuador, Bolivia y Chile. Diferencia, colonialismo y anticolonialismo. Quito: Ediciones Abya Yala, 2013. 